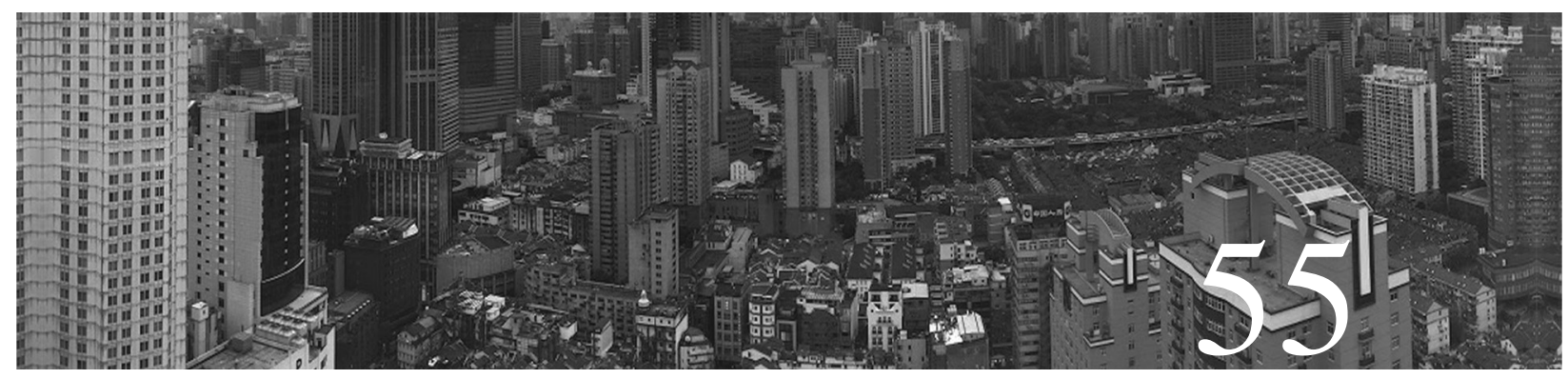

\title{
Media Since 1949: Changes and Continuities
}

\author{
Jian Xu and Wanning Sun
}

\section{INTRODUCTION}

As an integral aspect of Chinese politics, society and economy, Chinese media both embody and reflect the profound political and social transformation which China has witnessed from the establishment of the People's Republic of China (PRC) to the present. Taking a historical approach and through the prism of media professionals, technologies, and institution of journalistic production, this chapter aims to chart both the changes and continuities in the relationship between Chinese media and Chinese politics over the past six decades. In other words, focusing on the changing role and function of the Chinese state in shaping the direction and substance of media and political communication, we sketch China's media transformation in three historical stages, namely the socialist era (1949-1978); economic reform era (1979-2003) and post-reform authoritarian era (2003-present). The three periods are divided by two turning points. China's economic reform and opening-up started in 1978. The year 2003 marks the completion of the first phase of economic reform as well as the rise of online public discussion.

Such periodization as we have adopted here has two objectives. First, we aim to highlight the key moments in China's political, economic and social formations as well as the major ways in which the media constitutes these formations in each of these eras. Second, we want to bring into sharper relief the overlap and interconnection between these eras. We argue that a constellation of forces, including the Party-state, market, technologies and society have contributed to the transformation of China's media and communications in the last few decades. We further demonstrate that to understand how the Chinese media has evolved 
entails, therefore, a careful investigation into the competition, negotiation, interaction and mutual adaptation among these forces.

While our periodization is along the line of political and social change, our discussion will make it clear that each era also parallels the emergence and development of particular media and communication technologies. For instance, the socialist era was predominantly associated with print media and radio broadcasting; television featured prominently in the era of economic reform and a postreform authoritarian regime coincides with the gradual entrenchment of digital media. We demonstrate the dramatic changes and transformation in the traditional media as a consequence of the arrival of the new media. But more importantly, our discussion cautions against a simplistic and linear relationship between the 'old' (traditional media such as press, radio and television) and 'new' (digital and online media and communication technologies).

Finally, our attempt in establishing and delineating the connection between these various eras is motivated by a desire to understand the distinct formation and trajectory of China's journey towards modernity. We demonstrate that changes and continuities in China's media sector offer the most compelling evidence of the specific ways in which China and the Chinese people have created, experienced and engaged with various stages of the modernization process.

\section{THE SOCIALIST ERA (1949-1978)}

The PRC was established in 1949. As a newly established Communist nationstate, China followed the Soviet model to pursue socialist modernization in nearly all aspects of society, including industry, education, government administration, urban planning, media and so on (Bernstein and Li, 2010). The Chinese media strictly followed a 'commandist system associated with Communist ideology' (Pan, 2000: 73), which was derived from the Soviet model and guided by 'Soviet Communist theory', which required the state to have absolute power to control all media in order to serve the working classes and their interests (Siebert, Peterson and Schramm, 1956). In this model, mass media function as 'a major manufacturer and distributor of ideology and culture' (Cengiz, 2015: 259) and work for the Communist Party's persuasion, propaganda, education and mobilization (Siebert, Peterson and Schramm, 1956). The legacies of the Soviet media model and its guiding theory cast a long shadow on the PRC's media development and media work, especially before the economic reform in the late 1970s.

Built out of the Soviet model, Chinese media under Mao's leadership were run and managed by the Chinese Communist Party (CCP). They were the Party's 'throat and tongue' and worked as the CCP's ideological apparatus for mass persuasion, political mobilization, national integration and propaganda (Chu, 1978; Liu, 1971; Yu, 1964). Though the new regime initially allowed a small number of commercial newspapers and radio stations in a few major urban cities to continue, 
they quickly disappeared due to the Party's subsequent socialist transformation (Zhao,Y. 1998). By 1953, the Chinese government accomplished the socialist transformation of private ownership and established a highly centralized planned economy. Accordingly, all media became state-owned and a fully governmentsubsidized socialist media system was set up.

With the CCP's flagship, People's Daily, occupying the commanding height, official newspapers of Party committees at all levels formed a nation-wide Party newspaper network. Xinhua, the official press agency of the PRC established in 1931, together with the China News Service, founded in 1952, constituted China's national press agency network (Huang, 2009). In the broadcasting sector, centered around China National Radio Station established in 1949, the government set up a network of 'people's radio' stations (Zhao, Y. 1998). China's first TV station, Beijing Television, the predecessor of China Central Television (CCTV), started broadcasting in 1958. Subsequently, some provincial TV stations were established. In administration, newspaper offices, radio and TV stations were directly led by central and provincial Party committees and propaganda departments. In practice, they had to follow the 'Party principle' (dangxing yuanze) to work. The principle required media to accept the Party's guiding ideology as its own, propagate the Party's programs, policies and directives, and accept the Party's leadership and adhere to the Party's organizational principles and press policies (Zhao,Y. 1998). In terms of media content, political information dominated nearly all media channels, supplemented with limited edutainment to promote the effectiveness of propaganda. Media workers were highly subservient to the Party's commands and charged with two core responsibilities: educating the masses and resisting the forces of imperialism (Keane and Sun, 2013).

In the initial stage of the era, Chinese media experienced a relatively liberal period of development. Remaining non-Communist political parties (widely known as 'democratic parties') and social organizations were allowed to run their newspapers and express opinions, such as the Guangming Daily established in June 1949 by the Chinese Democratic League (Zhao, Y. 1998). Especially during the Hundred Flowers Campaign starting in 1956, when the CCP encouraged the 'democratic parties', intellectuals and citizens to openly express their opinions of the CCP, media had a brief period of liberalization and functioned as a platform for public expression, discussion and debate. However, the Anti-Rights Campaign in 1957 against those who criticized the CCP ended the emerging trend of pluralization and liberalization of media.

In the next two decades, Chinese politics were shaped by intra-Party struggle and class struggle. Media were manipulated by the CCP to propagandize and mobilize a series of CCP-led political campaigns, such as the Anti-Rightist Movement (1957-1959), the Great Leap Forward (1958-1961) and the Cultural Revolution (1966-1976). Journalism had to strictly adhere to the 'Party principle' and serve the Party's political needs. For example, the CCP used media to fabricate a large amount of false news to exaggerate production figures in 
agriculture and industry to promote the Great Leap Forward, while concealing the Great Famine that caused the death of millions of Chinese in the same period (Zhang, 2011).

In this period, wired radio was arguably the most effective mass media for nation-building, political mobilization and material production, as press circulation and people's literacy were low, especially in the vast rural area. As a carrier of modernity and public facility, wired radio loudspeakers were compulsorily installed in squares, factories, schools, villages and individual families. They were switched on and off mandatorily to air mostly political news programs broadcast by China National Radio Station and local radio stations. This collective and compulsory way of listening to the radio became a political ritual for Mao-era citizens. From 1958 to 1977, the number of wired radio loudspeakers increased from three million to 110 million ( $\mathrm{Xu}, 2014)$. Listening to radio had created a "nationalized synchronicity', through which, the voices of the Party-state 'coercively entered the private life of people' and 'a space of national integration' was constructed in the air $(\mathrm{Xu}, 2014:$ 105). The radio listeners were objects of propaganda and constructed entities. In Mao Zedong's words, they were 'blank sheets of paper' on which 'the most beautiful characters could be written' (Mao, 1971: 500). They were turned into masses with revolutionary fervor in the CCP-initiated political campaigns or obedient socialist citizens in everyday life. It was not until China's economic reform in 1978 that active and critical audiences started to emerge.

\section{THE ECONOMIC REFORM ERA (1978-2003)}

The 3rd Plenary Session of the 11th CPC Central Committee held in 1978 initiated China's economic reform and open up era. The key task of the CCP had been shifted from 'class struggle' in the Cultural Revolution to economic development and the construction of socialist modernization in the post-Mao era. In the media sector, China has experienced an unprecedented media boom. Radio and television stations, limited to central and provincial levels in the Mao era, started to expand to the municipal and county levels, following the pattern of 'four-level development and management' (Sun and Gorfinkel, 2016). The instrumental role of media as a tool for 'class struggle' declined. Instead, the economic and cultural functions of the media were promoted to satisfy ordinary people's everyday information needs and boost economic growth (Lewis, Martin and Sun, 2012). The 'rules of news', such as its 'truthfulness', 'objectivity', 'brevity' and 'liveliness', became increasingly valued in journalistic work, which led not only to the rise of the professionalization of Chinese journalists but also a diversity of news reporting (Zhao, Y. 1998: 34).

In 1978, the Ministry of Finance approved People's Daily and other seven media outlets to engage with experiments which aim to transform media into a 'public institution with enterprise-style management' (shiye danwei qiye guanli). The 
method was soon adopted nationally and media's day-to-day operation became less controlled by the Party and the government (Chen, 1999). In the meantime, the government began to withdraw direct subsidies from media organizations and open the market for media advertising. Advertising gradually became an important source of income for Chinese media (Zhao, Y. 1998). In the initial stage of economic reforms, many, both inside and outside China, expected them either to go hand in hand with or to herald the arrival of political reform. In this light, the roles of media, particularly their function vis-à-vis the political objectives of the Party, became controversial questions which directly impacted on the prospects of the Party's political reform. This is precisely what the heated debate on the function of media in the mid-1980s in China's press circles was about. The notions that 'news should be different from propaganda' and 'media should have multiple functions beyond merely serving politics' resonated among journalists, challenging the instrumentalism of Chinese media as the Party's propaganda tool (Meng, 2000). In the late 1980s, some chief editors of national newspapers openly expressed a desire for greater editorial independence and autonomy to pursue press freedom (Zhao, Y. 1998). Particularly under the short leadership of Zhao Ziyang from 1987 to 1989 , the CCP's control over media was rarely draconian. Media's roles in 'supervision by public opinion' (yulun jiandu), informing the people and facilitating public discussion on important issues were affirmed, forming an emerging discourse on the democratization of Chinese media (Zhao, Y. 1998). In the meantime, alternative periodicals (minjian kanwu) run by poets, university students, social activists and public intellectuals flourished, which radically criticized current social problems and advocated for political reforms (Wen, 2009). The democratization discourse presented in both the state and alternative media constituted one of the most important forces that drove the 1989 pro-democracy movement.

In the 1989 student movement, hundreds of journalists joined the protesters and many state media presented sympathetic coverage of the student demonstrations (Edwards, 2001). Chinese students and intellectuals also made use of foreign short-wave radio broadcasts, especially Voice of America, to follow the comments on the movement from international societies (Zhao and Hackett, 2005). The domestic and foreign media, together with alternative media, such as posters, leaflets and underground periodicals, played the most important role in legitimizing, mobilizing and spreading the movement.

With the crackdown on the pro-democracy movement in 1989, the Chinese government soon adjusted its reform direction and set up a new reform model 'economic reform without political reform' (Zheng and Lye, 2005). In the media sector, the Party re-imposed tight political control on media in case it went out of control again. The emerging trend of media democratization since the mid-1980s was nipped in the bud. Media reform re-shifted its focus to media commercialization, aligning with the new reform model. Especially after Deng Xiaoping's inspection tour of south China in early 1992, the CCP abandoned its ideological orthodoxy and adopted a pragmatic approach to economic growth, and rapid 
commercialization for market profit became a trend of Chinese media. The government intended to reinvigorate the media industry as part of boosting China's economic growth by bringing in market competition in the media sector, but in the meantime ensure not to lose ideological control and leadership over the commercialized media.

Since then, increasingly fierce market competition has forced media to better serve the needs of audiences, and thereby enhanced its role as an information and entertainment provider, and sometimes government watchdog (He, 1998). This led to the proliferation of media outlets, such as the dramatic rise of metropolitan newspapers (tabloids) and evening newspapers that cater to the interests and tastes of ordinary readers in the late 1990s, as well as the diversification of media content to cover business, health, sports, environment, culture, entertainment, international affairs and civic news. The number of newspapers, TV and radio stations increased from 382, 38 and 114 respectively in 1980 to about 2,000, 3,000 and 1,200 in the mid-1990s (Li and Lin, 1999). However, the rapid commercialization of the media sector had weakened the Party-state's control of media content and caused the fragmentation and decentralization of the media structure (Zhao, 2000a).

To keep media commercialization within the orbit of the Party-state, the Party adjusted its policies and management to re-centralize and rationalize media structure to retain its effective control. The State Press and Publications Administration tightened the issuing of licenses in the mid-1990s and completely stopped issuing new licenses in 1995 (Zhao, 2000a). Moreover, the government started to create media conglomerates to achieve the integration of political control and profit maximization (Zhang, 2011). In January 1996, China's first media conglomerate, Guangzhou Daily Press Group, was established. The government's concern about the potential competition from transnational media conglomerates in the West after China's entry into the World Trade Organization (WTO) in 2001 also accelerated the process of conglomeration (Zhang, 2011). By 2003, the conglomeration of Chinese media was basically completed. Sixty-nine media groups were approved and established, including 38 press groups, 13 TV and radio groups, one periodical group, nine publishing groups, five circulation groups and three film groups (Wang, 2004). However, in contrast to media conglomeration in the West, China's media conglomeration seldom resulted from market competition, but rather from administrative orders. It was a 'hallmark for China's bureaucraticauthoritarian state capitalism at work', causing Chinese media to be popularly referred to as 'Chinese Party Publicity Inc.' (Lee, He and Huang, 2006).

China's media reform, mainly through the state-guided marketization and conglomeration, has resulted in the formation of China's current 'dual-track' media system. On the one hand, the market mechanism is harnessed to stimulate the development of the media industry; on the other hand, the Party still controls and censors media and decides the assignment of their top personnel. Hence, Chinese media are caught between what Yuezhi Zhao (1998) calls the 'Party line' and the 'bottom line'. The media reform has not only restructured China's media 
landscape and re-established the nature of media system, but also rejuvenated journalistic practices, cultivated new types of journalists, innovated the CCP's propaganda work and generated fragmented audiences.

Investigative journalism was one of the most significant developments of Chinese journalism during the 1990s (de Burgh, 2003; Tong, 2011; Zhao, 2000b). The market competition in the media industry required media to produce a new genre of journalism that is different from the Party journalism to attract advertisers and subscribers. Investigative journalism, which often exposes scandalous news and social problems, had great market value. The other reason for the rise of investigative journalism was the Party's political need to 'reassert control over an unruly and dysfunctional bureaucracy' caused by the rapid economic reform (Zhao, 2000b: 580). Investigative journalism was therefore welcomed by the $\mathrm{CCP}$, because it could monitor local governments, promote public trust in leadership and create a positive environment for further reform.

In 1994, CCTV launched its daily investigative program Focus (Jiaodian fangtan), which featured hard-hitting reports on corruption and government wrongdoings. The next year, Southern Weekend of the Guangzhou-based Southern Daily Group became the first print media to embark on investigative reporting. The show and the newspaper soon proved to be highly successful in the marketplace, and inspired a nation-wide tide of investigative reporting programs, columns and media (Tong and Sparks, 2009). However, China's heavily controlled media system means that the supervisory function of Chinese investigative journalism is precarious and limited. It only focuses on 'specific issues', deals with 'concrete problems', and is therefore 'practical-minded' (Zhao, 2000b: 579). Metaphorically speaking, it hunts down 'flies, not tigers'. It works at the behest of the Party as a watchdog 'on the Party's leashes' (Zhao, 2000b). Nevertheless, the 'supervision by public opinion' that investigative journalism advocates and performs has gone deeply into the minds of journalists, government officials and the public. The supervisory power of investigative journalism had successfully set the agenda for and pushed the government to solve a wide range of controversial issues, such as judicial injustice, public health, environmental crises and corruption of Party officials (Tong, 2011).

Media reform has also created new types of Chinese journalists. The stereotype that sees Chinese journalists as the 'mouthpiece' of the CCP is incapable of explaining the changes in the professional role of Chinese journalists in the reform era, as media workers are required to pursue professionalism, market profit while accomplishing the Party-assigned propaganda work, which is inherently contradictory and hard to balance. Jonathan Hassid (2011) classifies contemporary Chinese journalists into four types. They are the 'Communist professionals', 'Americanstyle professionals', 'workday journalists' and 'advocate professionals'. The first type refers to those who follow the 'Party principles' to work, which constitutes the majority of Chinese journalists. The other three types have emerged since 1978. The 'American-style professionals' are dedicated to independent, objective and accurate reporting and follow the Western codes of ethics in journalistic practices. 
The 'workday journalists' are those who work for money and lack a commitment to public service. They are unethical and corrupt and sometimes violate regulations and laws. The 'advocate professionals' are those liberal-minded and contentious journalists who speak for the marginalized social groups through investigative reporting or advocacy. They are likely to make political mistakes and get punished for their bold speech. The emergence of new types of journalists has demonstrated the changing notions and practices of journalism within a controlled and propagandistic tradition of Chinese media under rampant commercialization.

In the economic reform era, television replaced radio as the most popular electronic mass media. The CCP started to proactively use television for nationbuilding and propaganda by staging Chinese-style media events (Sun, 2014). Different from media events in the West, where organizers, media producers and audiences are 'three contractual partners' (Dayan and Katz, 1992), Chinese-style media events are authoritarian in nature because the media producer, CCTV, is required by the event organizer, the $\mathrm{CCP}$, to promote its propaganda work $(\mathrm{Xu}$, 2016). The annual Spring Festival Gala run by CCTV since 1983 is a widely studied case in point (Sun, 2007; Zhao, B. 1998). The carefully designed entertainment show that broadcasts live on the eve of Chinese New Year to Chinese people at home and abroad 'delivers strong messages of patriotism and national unity' and 'demonstrates the ingenuity of the Chinese state in reinventing ways of indoctrinating and educating the nation' (Sun, 2007: 191). Besides ritual celebrations, contests and commemorations are also ideal occasions to produce televised national events, such as the live broadcast of the Chinese Women's Volleyball Team's finals with Japan in the 1981 Volleyball Women's World Cup and China's 50th National Daily Military Parade in 1999.

China's rapid economic growth has also given rise to consumerism and generated consumer citizens. With the increase in social stratification, the passive mass audiences in the Mao era began fragmenting into many subcultures or potential publics (Donald and Keane, 2002). Their growing individuality enabled them to become critical audiences who could select their favorite media commodities and criticize those they dislike. The circulation of press, audience rating and advertising revenue, have become new standards to measure the success of media in market competition. The controlling power of media content production is no longer absolutely dominated by the Party-state, but has started to shift to the hands of entrepreneurs and market forces to cater to the tastes of active audiences (Donald and Keane, 2002).

\section{THE POST-REFORM AUTHORITARIAN ERA (2003-PRESENT)}

In 2003, the 3rd Plenary Session of the 16th CCP Central Committee adopted the 'Decision of the CCP Central Committee on Several Issues in Perfecting the Socialist Market Economy'. The decision indicated that China had completed 
the first phase of economic reform and was now shifting focus to solving problems caused by it, as well as deepening economic restructuring. Therefore, Chinese academia widely uses the year of 2003 as the start of China's 'postreform' era (Bai and Wu, 2012). In this era, the rise of the Internet, and its profound social and political impacts, have arguably been the most prominent characteristics of Chinese media, society and politics.

\section{The Development of China's Internet and Social Media}

In 1987, the first e-mail, titled 'Crossing the Great Wall to Join the World', was sent from a Chinese address, marking the beginning of China's Internet history. In 1994, China realized a full-function linkage to the Internet and officially came online. With only about 10,000 Internet users in 1994, China's online population dramatically increased to 710 million by June 2016 (China Internet Network Information Center (CNNIC), 2016). The initial purposes for the Party-state to develop the Internet were to strengthen China's military power and boost economic growth (Zheng, 2007). However, the unexpected rapid development of the Internet has also transformed the life-styles and political engagement of ordinary Chinese, the governance of the Party-state, traditional journalistic practices, as well as the state-society relations.

From 1995 to 2009, Bulletin Board System (BBS) and weblogs (blogs) constituted the most important platforms for online public communication. The BBS forums, such as 'Tianya Community' (Tianya shequ) and 'Strong Nation Forum' (Qiangguo luntan), consisting of hundreds of discussion boards and millions of threads and posts, opened up virtual communities for ordinary people to share and affirm information and opinion on a wide range of topics when mainstream media were tightly controlled (Yang, 2003). Weblogs emerged in China in 2002. Mainly based on specialized blogging sites, such as Bokee, Blogchina, and China's three major commercial portals, Sina, Sohu and NetEase, user-generated blogs provided an individual but public space for Chinese people to represent themselves, establish networks, show personalities and form identities. The number of bloggers in China skyrocketed from 510,000 in 2002 to 221 million in 2009 (White Paper on China's Blogs, 2010). However, the number of active users of BBS sites and blogs dramatically declined with the arrival of China's social media era.

In August 2009, Sina Corporation launched its microblogging service - Sina Weibo, akin to a hybrid of Twitter and Facebook. Due to the blocking of Western popular social media sites in mainland China, China's home-grown and stateapproved social media are growing fast. Following Sina Weibo, Tencent, NetEase and Sohu soon started running their own Weibo service. Technologically, Weibo integrates the elements of BBS, blogs, instant-messaging systems and audiovisual sites, making it a real multifunctional media platform. By June 2013, China's Weibo users had reached 330 million, the highest since its emergence (CNNIC, 2013). Though still tightly controlled and censored as BBS, blogs and other news websites, the technological advantages of Weibo and its large 
numbers of subscribers have helped netizens to 'publicize and express their discontent' and posed 'a new challenge to the state regime of information control' (Sullivan, 2013).

In January 2011, Tencent released its Weixin service, known in English as WeChat, a counterpart of LINE and WhatsApp. It provides hold-to-talk voice messaging, text messaging, photo and video sharing, online payment, games and many other services. The number of monthly active Weixin users in China and overseas had climbed to 762 million in the first quarter of 2016 (Statista. com, 2016), making it unquestionably the most popular social media in China. Compared with Weibo, which is more like a 'public forum' where users can follow anyone, repost and comment on posts, Weixin is a semi-private platform where users are only visible to a circle of accepted friends. It is more effective for small group communication, but could not replace the role of Weibo in public discussion and mobilization, especially in public events.

The emergence and popularity of new online platforms does not mean the previous platforms have perished. Internet users usually travel across multiple platforms and make cross-platform information flow possible. The above-mentioned platforms, together with Baidu (the most popular search engine), Youku and Tudou (the most popular audio-visual sites), Taobao and JD.com (the most popular B2B sites), QQ (the most popular instant messaging software before Weixin) and many other specialized websites, provide a rough picture of China's Internet landscape for ordinary people's everyday entertainment, information needs, online shopping, social networking, self-expression and political engagement. Everyday digital media practices have formed a culture of circulation through netizens' consumption-cum-production and caused long-term political impact as they 'influenced the way people think about politics, culture and society' (Yu, 2007: 424).

However, the everyday online practices of Chinese people are not free but tightly controlled. The Chinese government has long censored mass media to avoid media's potential subversion of its authority (B. Xu, 2015). In the Internet age, the government has developed a wide variety of regulations, laws and methods to censor the Internet. The Internet censorship can be mainly divided into two types. The first type is that the government uses the 'Great Firewall of China' to filter IP (Internet Protocol Address) and DNS (Domain Name Server) of websites to prevent Chinese residents from accessing some foreign websites, such as Facebook, YouTube and Twitter (Bamman, O'Connor and Smith, 2012). The second type is that the government allows access but polices content of domestic websites. This includes the search blocking of ever-changing politically sensitive keywords and deleting posts and comments that contain such keywords, such as Falun Gong, Tibetan independence (zangdu) and democracy movement (minyun) (Bamman, O'Connor and Smith, 2012). The second type of censorship is mainly carried out through Internet service providers' self-censorship. Any Internet service provider that refuses to censor its content in accordance with Chinese law is unlikely to survive in China's Internet market. 


\section{Political Impacts of the Internet and Social Media}

China's Internet and social media have attracted extensive scholarly attention, especially to the political effects of the development of the digital technologies. The current research on China's Internet, as Guobin Yang (2014) states, has been largely explored within the 'dichotomous analytical categories' of the state vs. citizens, and authoritarianism vs. democracy. Thus, the rapidly growing body of literature mainly falls into two camps. One is enthusiastic about the empowering aspects of new media technologies to facilitate the formation of civil society and promote China's democratization (Tai, 2007; Yang, 2009; Yu, 2009). The other emphasizes authorities' regulations and censorship of the Internet as well as the government's adaptive uses of digital technologies in authoritarian governance (Han, 2015; MacKinnon, 2011; Schlæger and Jiang, 2014). Researchers of the first camp are usually techno-optimists and cautiously affirm the liberalizing and democratizing effects of the Internet. Researchers of the second camp are usually techno-pessimists and contend that the potential of online collective actions to democratize China is limited due to the regime's effective management of and active adaptation to the technological developments.

The discussion of online political engagement of ordinary Chinese and digital democracy in China has picked up since 2003. In 2003, online public opinion for the first time in Chinese history demonstrated the power to push the government to respond to and solve public crisis and controversial social issues, such as in the SARS epidemic ${ }^{1}$ and the case of Sun Zhigang. ${ }^{2}$ Therefore, Chinese media have dubbed 2003 'the year of online public opinion' (wangluo yulun nian). Since then, a year has seldom passed without 'Internet studies' (wangluo shijian) which have been widely studied by Chinese Internet scholars. Scholars mainly focus on the analysis of different modes of online activism and their political impacts by examining heterogeneous Internet events on environmental issues, official corruption, rights-defense issues and social unrests (Qiu and Chan, 2011). The activist practices of Chinese netizens are essentially constituted by $e$ 'gao and weiguan.

E'gao is a Chinese term for online spoofing practice, which could be a clever wordplay or skillful multimedia manipulation of texts, audio and visual materials. It often uses techniques such as punning, pastiche, burlesque, lip-synching and remixing of digital footage to poke fun at mainstream culture, value and power ( $\mathrm{Yu}$ and $\mathrm{Xu}, 2016)$. It is argued that e'gao is an alternative means for ordinary Chinese to articulate political critique and intervene in social realities through digitized humor, satire and parody (Meng, 2011; Voci, 2010). These rhetorical expressions could tactically avoid using sensitive keywords to circumvent Internet censorship. They are effective means to publicly express and display subversive emotions that resonate among participants in the Internet events.

Weiguan, literally translated as 'circle watch' or 'surrounding gaze' in English, refers to crowd gatherings around public spectacles and in public venues. The term has been popularly used as a cultural metaphor to illustrate the phenomenon 
of virtual crowd gathering in China's cyberspace to discuss public outcry and popular sentiment around offline controversial social issues. It is a popular form of 'mediated mobilization' (Lievrouw, 2011) that usually results in high volumes of online traffic by attracting millions of netizens' reading, sharing, reposting, commenting and discussing on the online forums and social media sites. Through weiguan, public emotion and sentiment are highly mobilized and tend to form networked power and group pressure to promote the transparency and resolution of controversial events (J. Xu, 2015). Weiguan is essential in online petitions, virtual sit-ins, cyber-vigilantism and has become a synonym of networked collective actions. In China, where people's freedom of association and assembly for political purpose is restricted, weiguan has enabled ordinary Chinese to engage in social and political issues in a relatively safe way by using affordable new media technologies. It constitutes the most important component of China's 'new citizen activism' (Yang, 2009) in the digital age.

Some of the existing scholarship on online activism sees activist uses of the Internet as proof of its role as an alternative space to express views, network and participate in public issues, empowering marginalized social groups, such as migrant workers (Qiu, 2009; Wallis, 2013) and civil rights defendants (Teng, 2012) and giving rise to a fledgling civil society against China's oppressive authoritarian regime. Other scholars, however, point out China's online activism is almost exclusively practiced in 'radical communicative actions conducted in words and images' (Yang, 2008: 129) and only focuses on the resolution of specific controversial issues with little offline actions (Zheng and $\mathrm{Wu}, 2005$ ). It is more likely to be episodic, spontaneous and lacking in formal organization (Yang, 2006). Besides, the government's rigorous control and censorship on the Internet also explain why large-scale Internet-facilitated collective actions with clear political pursuits, such as the Arab uprisings and and the Occupy Movement in the early 2010s, in which social media successfully facilitated pro-democracy protests in Arab countries and a transnational social movement against social and economic inequality, would be unlikely to occur in the Chinese context.

Researchers who focus on government control mainly study how governments at different levels use 'hard' and 'soft' tactics to manage the Internet and social media. Marolt (2011) argues that online postings that 'either criticize China's Party-state and its policies directly or advocate collective political action' are likely to be censored. However, King, Pan and Roberts (2013) analyze the content of millions of social media posts on nearly 14,000 social media services in China and find that critical posts against the state, its leaders and policies are not more likely to be censored. Instead, the posts that spur collective activities are the ones that tend to be censored. MacKinnon (2009) explores how Chinese Internet companies censor user-generated content in the blogosphere. Her research reveals that domestic censorship varies from company to company. The choices and actions of private individuals and companies significantly impact the dynamics between freedom and control in the Chinese blogosphere. 
Besides the notorious censorship, the government also applies relatively softer tactics to control online activism. With the rise of Internet events, the Propaganda Department of the Central Committee of the CCP established the Bureau of Public Opinion in 2004 to collect, analyze and report public sentiments to enable the CCP to respond to issues of public concern in a timely fashion (Brady, 2008). Subsequently, propaganda departments of local governments also set up offices of public opinion to monitor local public sentiments. The state media, People's Daily and Xinhua, also established their public opinion monitoring centers to provide public opinion reports to governmental organizations and industries $(\mathrm{Hu}$, 2017). In addition, governments at different levels also employ a large number of online commentators, popularly dubbed as the 'Fifty-Cent Party' (wumao dang), to post comments favorable towards the government to sway public opinion, particularly when the government has to defend their credibility on controversial social issues (Han, 2015).

Moreover, the government actively adapts to new media platforms for effective governance. As soon as Weibo became a popular platform for netizens to air their discontent and form online public sentiment (Sullivan, 2013), central and local governments started to run their official Weibo accounts to interact with the public and improve their social management and political legitimacy (Schlæger and Jiang, 2014). By December 2013, a total of 183,232 Weibo accounts had been opened by governmental agencies on China's four major Weibo service providers (Sina, Tencent, People.cn and Xinhuanet). The number of Weibo accounts opened by the CCP and governmental cadres had reached 75,505 (Xinhuanet, 2014). With the popularity of WeChat, more and more governmental organizations have set up their WeChat public accounts to regularly send messages to their subscribers. The purpose of the Party and government in occupying popular social media platforms is clearly seen in President Xi Jinping's speech at the Cybersecurity and Informatization Work Conference in April 2016. He stated:

\footnotetext{
[W] herever the masses are, there our leading cadres must go as well. All levels' Party and government bodies, as well as leading cadres, must learn how to march the mass line through the network, regularly go online to look around, understand what the masses think and want, collect good ideas and good suggestions, and vigorously respond to netizens' concerns, relieve their doubts and dispel their worries. (China Copyright and Media, 2016)
}

The deliberative uses of social media embody the CCP's adaptability and resilience in governance in the digital era. Scholars in political sciences consider these uses as integral to 'responsive authoritarianism' (Stockmann, 2015), 'authoritarian deliberation' (He and Warren, 2011) or 'authoritarianism 2.0' (Mertha, 2009), all of which compete with the liberating and democratizing effects of the new media.

As discussed above, the 'empowerment hypothesis' and 'repression hypothesis' have dominated studies of China's Internet. Some scholars critique the dichotomy as problematic and advocate a shift of focus from democratization vs. control to the relational dynamics between the Party-state, the Internet and civil society (Meng, 
2010; Yang, 2009; Yuan, 2015). Meng (2010) proposes to use the sociological term 'mediation' to study the mediating power of the Internet at three interrelated levels, namely the institutional, the symbolic and the individual, to overcome the limitation of the democratization approach. Yuan (2015: 222) suggests studying the 'structuration process of new political-networked communication and new forms of political association' to unpack the dynamics between the changing social structures and cultural agency enabled by new media communication in the Chinese society. Yang (2009) uses 'multi-interactionism' as an analytical approach to study the interactions and mutual adaptations of multiple parties involved in online activism, such as the state power, culture, market and transnationalism.

The rise of the Internet has generated new forms of digitized political communication, transformed state-society relations and brought about innovative journalistic practices. Yu (2011) studies how j-bloggers (journalist bloggers) experimented amateur journalism beyond their work in the mainstream news media. She argues that blogging enables journalists to watch, poke and mock their professional work in a relatively independent space, facilitating the audiences to understand their struggles, emotions and beliefs behind the news stories. Some scholars investigate why and how Chinese journalists embrace new media in their everyday journalistic practices. They argue that the Internet and social media could help journalists improve their commercial competitiveness, present new channels for fighting censorship and expand the boundaries of permissible reporting (Hassid and Repnikova, 2016). Moreover, the rise of the digital media technologies has enabled ordinary people to generate self-styled reporting and become 'citizen journalists' or 'grassroots journalists'. They can engage in on-the-ground reporting with mobile and digital cameras and disseminate it online, especially in times of crisis or regarding controversial social issues, when the crisis reporting or investigation of the mainstream media are constrained (Xin, 2010).

The advent of new communication technologies has also brought forth challenges and opportunities for traditional media worldwide (Garrison, 1996). In China, convergence between traditional and new media has become the main trend of media development. Facing market challenges and audience segmentation in the new media era, traditional media at both central and local levels are expanding their communication channels to the Internet and mobile media and adopting open publishing and broadcasting features to innovate traditional media practices. For example, CCTV launched China's first national Internet TV China Network Television (CNTV.cn) in December 2009. The site offers web broadcasting of all programs from CCTV's 20 channels and also provides online community network and video-on-demand services (Chen, 2009). People's Daily launched a free mobile app in June 2014 that allows the readers to read the entire newspaper content and give feedback and comments (People's Daily, 2014).

Media convergence has already become a national strategy. In August 2014, the Central Leading Group for Deepening Reform headed by President Xi Jinping issued the 'Guiding Opinions concerning Promoting the Converged Development 
of Traditional Media and New Media'. The official drive for converged development is to build novel communication patterns through new communication technologies and channels in response to China's deepening media reform and transformation. This national media strategy indicates that the government 'is determined to play the next "offensive gambit" of reform, starting with the strategic structure of the media, occupying the public opinion battlefield and grasping the initiative in a new media structure' (China Copyright and Media, 2014).

This converging development parallels Chinese media's global expansion. Since the 2008 Beijing Olympics, the Chinese government put the 'going global' policy on top of the government's agenda and increased investment in the state media to boost their global influence and promote the nation's soft power $(\mathrm{Hu}$ and Ji, 2012; Sun, 2014). CCTV now broadcasts six international channels in five languages and claims a total global audience of 125 million. Xinhua News Agency launched its English-language TV service, CNC World, which broadcasts English news programs 24 hours a day, in 2010. As Xinhua President Li Congjun said at CNC's launch ceremony, 'CNC will present an international vision with a China perspective. It will broadcast news reports in a timely way and objectively and be a new source of information for global audiences' (Xinhuanet, 2010).

China's state-led 'media going global' initiative, either viewed as 'external publicity work' (Nye, 2011) or 'public diplomacy through communication' (Wang, 2011), has significantly pushed the internationalization of Chinese media. Though the effectiveness of the initiative is still hard to evaluate at present, it cannot be denied that the government has realized that how to tell Chinese stories to win the minds and hearts of foreign publics and promote China's international image and soft power through media has become a matter of paramount importance.

\section{CONCLUSION}

The chapter examines the development of Chinese media with a historical approach and aims to demonstrate the continuities and changes of Chinese media in different historical periods. We argue that the evolution of Chinese media has not been a linear progression, but has been full of detours and digressions. To understand the evolution of Chinese media in any given historical moment, we should not focus on one particular aspect - be it political, technological or economical. Instead, we should consider how the forces compete, negotiate and interact to cause the change of direction in media development.

In all critical moments, the Party-state has played a decisive role. As demonstrated in a series of state-orchestrated reforms, such as media commercialization, conglomeration and globalization, the Party's control over media has not been weakened; instead, it has been enhanced with adaptability and innovation to manage the increasingly complex Chinese media system. Authoritarian 
control with precarious relaxation and contraction constitutes the most outstanding continuity of Chinese media since 1949. Besides, the Party-state has always actively sought to identify new and innovative ways of engaging new media and communication technologies of the time - be it press, radio, television and digital media - in propaganda work and political mobilization. There is no reason to expect the future of Chinese media, at least in the near future, to be more liberalized and democratized.

We also caution against a technologically deterministic view in understanding the relationship between traditional and new media in China. It is important to go beyond either an 'empowerment hypothesis' or 'repression hypotheses' to critically analyze the strategies, interplays and consequences of mediated political communication of both the state and non-state actors. The highly mediatized interplay between the Party-state and society has become normalized in China's digital age. The Internet is used as a 'microphone' by ordinary people to express discontent, criticize the authority and defend citizen rights. In the meantime, it is also a 'safety valve' for the Party-state to capture public opinion and respond to the public concerns. 'To solve online issues through online channels' has become a new principle for governments at all levels in dealing with crises and emergencies. We need to consider both the democratic and authoritarian uses of the new media technologies.

\section{Notes}

1 The Severe Acute Respiratory Syndrome (SARS) spread rapidly in China after November 2002. Initially, the government covered up the public health crisis and restricted media reporting. The information blackout soon provoked an online outcry, which effectively pressed the government to release real SARS information in April 2003 and later establish regulations and laws regarding crisis management. The SARS crisis is widely seen as a turning point of China's crisis communication (see Xu, 2016; Yu, 2009).

2 Migrant worker Sun Zhigang died at a detention center in Guangzhou in 2003 as a result of physical abuse by police. He had been detained under China's custody and repatriation system just because he could not provide his temporary residence permit during a routine check. His death received massive attention on the Internet. The strong public sentiment online pressed the government to punish the people responsible for Sun's death and abolish the custody and repatriation system (see Zhao, 2008).

\section{REFERENCES}

Bai, Y. and Wu, F. (2012). Hou gaige shidai de zhuyao maodun yu gaige renwu (Principle contradiction and reform tasks in the post-reform era). Jingjixue dongtai (Economics Trends), 8: 31-37.

Bamman, D., O'Connor, B. and Smith, N. (2012). Censorship and deletion practices in Chinese social media. First Monday, 17(3). DOI: http://dx.doi.org/10.5210/fm.v17i3.3943

Bernstein, T. and Li, H. (eds). (2010). China learns from the Soviet Union, 1949-present. Lanham, MD: Lexington Books.

Brady, A.M. (2008). Marketing dictatorship: Propaganda and thought work in contemporary China. Lanham, MD: Rowman \& Littlefield. 
Cengiz, G. (2015). Transition from Soviet-Communist media theory to new authoritarian media system: Turkmenistan and Azerbaijan media case. Revista de Stiinte Politice. Revue des Sciences Politiques, 47: 257-267.

Chen, H. (1999). Jiushi niandai zhongguo chuanmei zhidu yanbian (Institutional change of Chinese mass media in the 1990s). Ershiyi shiji (The 21st Century), 6(53): 4-14.

Chen, J. (2009). CCTV goes online to expand reach amid crackdown. Retrieved from www.chinadaily.com.cn/china/2009-12/29/content_9239283.htm

China Copyright and Media (2014). People's Daily: Telling China's story well in a new converged media structure. Retrieved from https://chinacopyrightandmedia.wordpress.com/2014/08/19/peoples-daily-telling-chinas-story-well-in-a-new-convergedmedia-structure/

China Copyright and Media (2016). Speech at the work conference for cybersecurity and informatization. Retrieved from https://chinacopyrightandmedia.wordpress. com/2016/04/19/speech-at-the-work-conference-for-cybersecurity-and-informatization/

Chu, G. (1978). Political media in China: Shaping new cultural patterns. Honolulu: University of Hawaii Press.

CNNIC. (2013). Di 32 ci zhongguo hulian wangluo fazhan zhuangkuang tongji baogao (The 32nd statistical report on Internet development in China). Retrieved from www. cac.gov.cn/files/pdf/hlwtjbg/hlwlfzzkdctjbg032.pdf

CNNIC. (2016). Di 38 ci zhongguo hulian wangluo fazhan zhuangkuang tongji baogao (The 38th statistical report on Internet development in China). Retrieved from www. cnnic.net.cn/hlwfzyj/hlwxzbg/hlwtjbg/201608/t20160803_54392.htm

Dayan, D. and Katz, E. (1992). Media events: The live broadcasting of history. Cambridge: MA: Harvard University Press.

De Burgh, H. (2003). Kings without crowns? The re-emergence of investigative journalism in China. Media, Culture \& Society, 25(6): 801-820.

Donald, S.H. and Keane, M. (2002). Media in China: New convergences, new approaches. In Donald, S.H., Keane, M and Yin, H, Media in China: Consumption, content and crisis. London: Routledge-Curzon, pp: 3-17.

Edwards, L. (2001). Mediapolitik: How the mass media have transformed world politics. Washington, D.C.: Catholic University of America Press.

Garrison, B. (1996). Successful strategies for computer-assisted reporting. London: Routledge.

Han, R. (2015). Manufacturing consent in cyberspace: China's 'Fifty-Cent Army'. Journal of Current Chinese Affairs, 44(2): 105-134.

Hassid, J. (2011). Four models of the fourth estate: A typology of contemporary Chinese journalists. The China Quarterly, 208: 813-832.

Hassid, J. and Repnikova, M. (2016). Why Chinese print journalists embrace the Internet. Journalism, 17(7): 882-898.

He, B. and Warren, M.E. (2011). Authoritarian deliberation: The deliberative turn in Chinese political development. Perspectives on Politics, 9(02): 269-289.

He, Z. (1998). Cong houshe dao dangying yulun gongsi: Zhonggong dangbao de yanhua (From mouthpiece to Party Publicity Inc: The evolution of the Chinese Communist Party's press). In He, Z. \& Chen, H. (eds), Zhongguo Chuanmei Xinlun (New Perspectives on the Chinese Media). Hong Kong: Taipingyang shiji chubanshe, pp. 66-107.

$\mathrm{Hu}$, Y. (2017). From yulun (public opinion) to yuqing (public sentiment): Their history and practice in China's information management. In Goggin, G. and McLelland, M. (eds), The Routledge companion to global Internet histories. New York: Routledge, pp. 516-528.

$\mathrm{Hu}, \mathrm{Z}$. and Ji, D. (2012). Ambiguities in communicating with the world: the 'Going-out' policy of China's media and its multilayered contexts. Chinese Journal of Communication, 5(1): 32-37. 
Huang, H. (2009). Xin zhongguo chengli yilai xinwen shiye fazhan de lishi guiji (Historical development of Chinese journalism since the establishment of the People's Republic of China). Xinwen jizhe (Shanghai Journalism Review), 10: 4-8.

Keane, M. and Sun, W. (2013). General introduction. In Keane, M. and Sun, W. (eds), Chinese media: Critical concepts in media and cultural studies (Volume 1). New York: Routledge, pp. 1-13.

King, G., Pan, J. and Roberts, M.E. (2013). How censorship in China allows government criticism but silences collective expression. American Political Science Review, 107(02): $326-343$

Lee, C.C., He, Z. and Huang, Y. (2006). 'Chinese Party Publicity Inc.' conglomerated: the case of the Shenzhen press group. Media, Culture \& Society, 28(4): 581-602.

Lewis, T., Martin, F. and Sun, W. (2012). Lifestyling Asia? Shaping modernity and selfhood on life-advice programming. International Journal of Cultural Studies, 15(6): 537-566.

Li, L. and Lin, H. (1999). Longduan, ziyou jingzheng, longduan jingzheng - Dangdai zhongguo xinwen meijie jituanhua quxiang touxi (Monopoly, free competition or monopolistic competition: Analysis of China's media conglomeration). Xinwen daxue (Journalism University), 2: 5-10.

Lievrouw, L.A. (2011). Alternative and activist new media. Cambridge and Malden: Polity Press.

Liu, A.P.L. (1971). Communication and national integration in Communist China. Berkeley: University of California Press.

MacKinnon, R. (2009). China's censorship 2.0: How companies censor bloggers. First Monday, 14(2). Retrieved from http://firstmonday.org/article/view/2378/2089

Mackinnon, R. (2011). China's 'networked authoritarianism'. Journal of Democracy, 22(2): 32-46.

Mao, Z. (1971). Selected readings from the works of Mao Tse-tung. Beijing: Foreign Language Press.

Marolt, P. (2011). Grassroots agency in a civil sphere? Rethinking Internet control in China. In Herold, D and Marolt, P. (eds), Online society in China: Creating, celebrating, and instrumentalising the online carnival. New York: Routledge, pp. 53-68.

Meng, B. (2010). Moving beyond democratization: A thought piece on the China Internet research agenda. International Journal of Communication, 4: 501-508.

Meng, B. (2011). From steamed bun to grass mud horse: E Gao as alternative political discourse on the Chinese Internet. Global Media and Communication, 7(1): 33-51.

Meng, J. (2000). Zhongguo dazhong chuanmei shiye de fazhan yu zhongguo minzhuhua jincheng (The development of China's mass media and China's social democratization). Jianghan xuekan (Jianghai Journal), 3: 40-48.

Mertha, A. (2009). 'Fragmented authoritarianism 2.0': political pluralization in the Chinese policy process. The China Quarterly, 200: 995-1012.

Nye, J.S. (2011). The future of power. New York: Public Affairs.

Pan, Z. (2000). Improvising reform activities: the changing reality of journalistic practice in China. In Lee, C.C. (ed), Power, money, and media: Communication patterns and bureaucratic control in cultural China. Evanston, IL: Northwestern University Press, pp. 68-111.

People's Daily. (2014). People's Daily launched free mobile app. Retrieved from http://en.people.cn/n/2014/0612/c98649-8740455.html

Qiu, J.L. (2009). Working-class network society: Communication technology and the information have-less in urban China. Cambridge, MA: MIT Press.

Qiu, J.L. and Chan, J.M. (eds). (2011). Xinmeiti shijian yanjiu (New media events research). Beijing: Renmin University Press. 
Schlæger, J. and Jiang, M. (2014). Official microblogging and social management by local governments in China. China Information, 28(2): 189-213.

Siebert, F., Peterson, T. and Schramm, W. (1956). Four theories of the press: the authoritarian, libertarian, social responsibility and Soviet communist concepts of what the press should be and do. Illinois: University of Illinois Press.

Statista.com. (2016). Number of monthly active WeChat users from 2nd quarter 2010 to 1st quarter 2016 (in millions). Retrieved from www.statista.com/statistics/ 255778/number-of-active-wechat-messenger-accounts/

Stockmann, D. (2015). Responsive authoritarianism in Chinese media. In deLisle, J. and Goldstein, A. (eds), China's challenges. Philadelphia: University of Pennsylvania Press, pp. 139-156.

Sullivan, J. (2013). China's Weibo: Is faster different? New Media \& Society, 16(1): 24-37.

Sun, W. (2007). Dancing with chains: Significant moments on China Central Television. International Journal of Cultural Studies, 10(2): 187-204.

Sun, W. (2014). Foreign or Chinese: Reconfiguring the symbolic space of Chinese media. International Journal of Communication, 8: 1894-1911.

Sun, W. and Gorfinkel, L. (2016). Television, scale and place-identity in the PRC: Provincial, national and global influences from 1958 to 2013. In Tay, J. and Turner, G. (eds), Television Histories in Asia: Issues and Contexts, London: Routledge, pp. 19-37.

Tai, Z. (2007). The Internet in China: Cyberspace and civil society. New York: Routledge.

Teng, B. (2012). Rights defence (weiquan), microblogs (weibo), and the surrounding gaze (weiguan): The rights defence movement online and offline. China Perspectives, 3: 29-41.

Tong, J. (2011). Investigative journalism in China: Journalism, power and society. New York and London: Continuum.

Tong, J. and Sparks, C. (2009). Investigative journalism in China today. Journalism Studies, 10 (3): 337-352.

Voci, P. (2010). China on video: Smaller-screen realities. London and New York: Routledge.

Wallis, C. (2013). Technomobility in China: Young migrant women and mobile phones. New York: New York University Press.

Wang, J. (ed.). (2011). Soft power in China: Public diplomacy through communication. New York: Palgrave Macmillan.

Wang, X. (2004). Zhongguo chuanmei jiegou yu shichang fen'er fenxi (Analysis of the structure and market share of Chinese media). Retrieved from www.china.com.cn/ zhuanti2005/txt/2004-02/27/content_5504166.htm

Wen, Y. (2009). Women de yizhi shi leguande: Zhongguo linglei chuanbo de shengji jiuzai jiafengzhong (We are optimistic: China's alternative media live in fissures). Xinwenxue yanjiu (Journalism Studies), 99: 251-264.

White Paper on China's Blogs. (2010). Zhongguo boke baidpishu (White paper on China's blogs). Retrieved from http://blog.sina.com.cn//m/8/2010/0907/158713.html

Xin, X. (2010). The impact of 'citizen journalism' on Chinese media and society. Journalism Practice, 4(3): 333-344.

Xinhuanet. (2010). Xinhua launches CNN World English Channel, Retrieved from http:// news.xinhuanet.com/english2010/china/2010-07/01/c_13378575.htm

Xinhuanet. (2014), 2013 nian zhongguo zhengwu weibo pinggu baodao fabu, woguo zhengwu weiboke shuliang jiao shangnian zengzhang 46\%, (2013 China's official weibo evaluation report was released. The quantity of official weibo accounts increased $46 \%$ than last year). Retrieved from http://news.xinhuanet.com/ politics/2014-04/08/c_1110140942.htm 
Xu, B. (2015). Media censorship in China. Retrived from www.cfr.org/china/mediacensorship-china/p11515

$\mathrm{Xu}$, J. (2015). Online weiguan in Web 2.0 China: Historical origins, characteristics, platforms and consequences. In Guobin Yang (ed.), China's Contested Internet. Copenhagen: NIAS Press of the University of Copenhagen, pp. 257-282.

$\mathrm{Xu}$, J. (2016). Media events in Web 2.0 China: Interventions of online activism. Eastbourne, UK: Sussex Academic Press.

Xu, M. (2014). Dianshi de xingqi: 1980nian zhiji zhongguo neidi dianzi meijie yu richang shenghuo (The rise of television: Electronic media and everyday life in mainland China in the 1980s). Wenyi yanjiu (Cultural Studies), 12: 103-115.

Yang, G. (2003). The co-evolution of the Internet and civil society in China. Asian Survey, 43(3): 405-422.

Yang, G. (2006). Activists beyond virtual borders: Internet-mediated networks and informational politics in China. First Monday, 11(9). Retrieved from http:// firstmonday.org/ojs/index.php/fm/article/view/1609

Yang, G. (2008). Contention in Chinese cyberspace. In O'Brien, K. (ed.), Popular protest in China. Cambridge, MA: Harvard University Press, pp. 126-143.

Yang, G. (2009). The power of the Internet in China: Citizen activism online. New York: Columbia University Press.

Yang, G. (2014). Political contestation in Chinese digital spaces: Deepening the critical inquiry. China Information, 28(2): 135-144.

Yu, F.T.C. (1964). Mass persuasion in Communist China. New York: Praeger.

Yu, H. (2007). Blogging everyday life in Chinese Internet culture. Asian Studies Review, 31(4): 423-433.

Yu, H. (2009). Media and cultural transformation in China. London and New York: Routledge.

Yu, H. (2011). Beyond gatekeeping: J-blogging in China. Journalism, 12(4): 379-393.

$\mathrm{Yu}, \mathrm{H}$. and $\mathrm{Xu}$, J. (2016). E'gao as a networked digital leisure practice in China. In McGillivray, D., McPherson, G. and Carnicelli, S. (eds), Digital leisure cultures: Critical perspectives. London: Routledge.

Yuan, E.J. (2015). The new political of mediated activism in China: A critical review. In Chen, W. and Reese, S.D. (eds), Networked China: Global dynamics of digital media and civic engagement: New agendas in communication. London: Routledge, pp. 214-230.

Zhao, B. (1998). Popular family television and party ideology: the Spring Festival Eve happy gathering. Media, Culture \& Society, 20(1): 43-58.

Zhang, X. (2011). The transformation of political communication in China: from propaganda to hegemony. Singapore: World Scientific.

Zhao, Y. (1998). Media, market, and democracy in China: Between the party line and the bottom line. Urbana and Chicago: University of Illinois Press.

Zhao, Y. (2000a). From commercialization to conglomeration: the transformation of the Chinese press within the orbit of the party state. Journal of Communication, 50(2): 3-26.

Zhao, Y. (2000b). Watchdog on Party leashes? Contexts and implications of investigative journalism in post-Deng China. Journalism Studies, 1(2): 577-597.

Zhao, Y. (2008). Communication in China: Political economy, power, and conflict. Lanham, MD: Rowman \& Littlefield Publishers.

Zhao, Y. and Hackett, R.A. (2005). Media globalization, media democratization: Challenges, issues, and paradoxes. In Hackett, R.A. and Zhao, Y, (eds), Democratizing global media: One world, many struggles. Lanham, MD: Rowman \& Littlefield, pp. 1-28. 
Zheng, Y. (2007). Technological empowerment: The Internet, state, and society in China. Stanford, CA: Stanford University Press.

Zheng, Y. and Lye, L.F. (2005). Political legitimacy in reform China. In White, L. (ed.), Legitimacy: Ambiguity of political success or failure in East and Southeast Asia. Singapore: World Scientific, pp. 183-214.

Zheng, Y. and Wu, G. (2005). Information technology, public space, and collective action in China. Comparative Political Studies, 38(5): 507-536. 